\title{
Soil moisture prediction of bare soil profiles using diffuse spectral reflectance information and vadose zone flow modeling
}

\author{
E. Babaeian ${ }^{\mathrm{a}, 1}$, M. Homaee ${ }^{\mathrm{a}, *}$, C. Montzka $^{\mathrm{b}}$, H. Vereecken $^{\mathrm{b}}$, A.A. Norouzi ${ }^{\mathrm{c}}$, M. Th. van Genuchten ${ }^{\mathrm{d}, \mathrm{e}}$ \\ a Department of Soil Science, Tarbiat Modares University, Tehran 14115-336, Iran \\ ${ }^{\mathrm{b}}$ Institutes of Bio- and Geosphere: Agrosphere (IBG-3), Forschungszentrum Jülich GmbH, 52425 Jülich, Germany \\ c Soil Conservation and Watershed Management Research Institute (SCWMRI), Tehran, Iran \\ d Department of Mechanical Engineering, COPPE/LTTC, Federal University of Rio de Janeiro, Rio de Janeiro, RJ 21945-970, Brazil \\ e Department of Earth Sciences, Utrecht University, Utrecht, Netherlands
}

\section{A R T I C L E I N F O}

\section{Article history:}

Received 23 August 2015

Received in revised form 3 October 2016

Accepted 12 October 2016

Available online 18 October 2016

\section{Keywords:}

Soil moisture

ASAR

Spectral reflectance

Soil hydraulic properties

Spectral transfer functions

\begin{abstract}
A B S T R A C T
Soil hydraulic property information of the vadose zone is key to quantifying the temporal and spatial variability of soil moisture, and for modeling water flow and contaminant transport processes in the near surface. This study deals with exploring the feasibility of using diffuse soil spectral information in the visible, near-infrared and shortwave infrared range $(350-2500 \mathrm{~nm})$ to estimate coarse-scale soil hydraulic parameters and predict soil moisture profiles using a topography-based aggregation scheme in conjunction with a 1D mechanistic water flow model. Three different types of parametric transfer functions (so-called spectrotransfer functions, STFs; pedotransfer functions, PTFs; and spectral pedotransfer functions, SPTFs) were aggregated from the point scale to $1 \mathrm{~km}^{2}$ pixel size. to provide coarse scale estimates of van Genuchten-Mualem (VGM) hydraulic parameters. The coarse scale hydraulic parameters were evaluated by simulating soil water dynamics of the $1 \mathrm{~km}^{2}$ pixels across the Zanjanrood River sub-watershed (ZRS) in northwest Iran. Resultant soil water states were compared with ground-truth measurements and advanced synthetic aperture radar (ASAR) estimates of soil water content. The topography-based aggregation scheme was found to provide effective values of the VGM hydraulic parameters across the ZRS study site. The coarse scale STFs performed best in terms of simulating surface, near-surface and subsurface soil water dynamics, followed by the coarse scale SPTFs and PTFs, which performed similarly. The average simulated soil water contents of the surface layer closely correlated with ASAR estimates during relatively wet periods. Simulated subsurface soil water dynamics matched well with the ground-truth measurements. These findings indicate the feasibility of using spectral data to predict VGM hydraulic parameters and, ultimately, to predict soil water dynamics at the larger scales.
\end{abstract}

(c) 2016 Elsevier Inc. All rights reserved.

\section{Introduction}

Profile soil moisture, as a key dynamic state variable, plays a central role in weather and climate predictions from the regional to the global scale by controlling the exchange and partitioning of water and energy fluxes between the land surface and the atmosphere (Vereecken et al., 2008; Kornelsen and Coulibaly, 2014). Accurate knowledge of profile soil moisture at various spatial and temporal scales is also important for strategic management of water resources (Vereecken et al., 2016). Soil moisture status and fluxes vary considerably in both space and time due to inherent variations in the soil hydraulic properties (Montzka et al., 2011), precipitation rates (Koster et al., 2004;

\footnotetext{
* Corresponding author.

E-mail address: mhomaee@modares.ac.ir (M. Homaee).

1 Present address: Soil, Water, and Environmental Science Department, The University of Arizona, Tucson, AZ 85721, USA.
}

Rosenbaum et al., 2012), topographic features (Joshi and Mohanty, 2010; Jana and Mohanty, 2012b; Schröter et al., 2015), and vegetation characteristics (Famiglietti et al., 1998; Guar and Mohanty, 2013).

A range of in-situ and remote soil water sensing techniques have been developed, tested, and used with varying levels of success during the past several decades (Vereecken et al., 2014). In-situ techniques are generally confined to short-term field experiments or point-scale sensor installations that are representative over a relatively small spatial scales since soil water is subject to considerable spatial heterogeneity (Greifeneder et al., 2016). Indirect estimates of soil moisture can be obtained using active (Ulaby et al., 1996; Baghdadi et al., 2012; Jagdhuber et al., 2013; Kornelsen and Coulibaly, 2013) and passive (Jonard et al., 2011; Montzka et al., 2013; Dimitrov et al., 2014, 2015) microwave remote sensors that have had the greatest success in estimating soil moisture in a spatially and temporally consistent behavior. These methods provide surface soil moisture estimates of only the top few centimeters $(0-5 \mathrm{~cm})$ of a soil profile (Kerr, 2007). The somewhat low spatial 
resolution (several tens of kilometers) of passive microwave measurements has prompted research on downscaling to expand applicability (Pellenq et al., 2003; Merlin et al., 2008). However, non-invasive geophysical methods, such as ground penetrating radar (GPR) (Weihermuller et al., 2007; Jonard et al., 2011), electromagnetic induction (EMI) (Robinson et al., 2012), and electrical resistivity tomography (ERT) (Vanderborght et al., 2013), have been used to bridge the gap between point and satellite measurements of soil moisture.

Soil-vegetation-atmosphere-transfer (SVAT) models are commonly used to numerically simulate state variables such as soil moisture, as well as for estimating energy-mass exchange fluxes. The performance of SVAT models is usually confined by uncertainty of the driving forces and its parameters. While soil hydraulic properties are very important in distributed SVAT models, they are mostly observed only at the point scale or generalized to soil maps. A major challenge when running these models at a larger scale is obtaining accurate model inputs and physically realistic hydraulic parameter values. Aggregation of soil hydraulic properties from field to watershed or regional scales is critical for SVAT model performance at these scales (Zhu and Mohanty, 2002a, 2002b; Vereecken et al., 2007; Jana and Mohanty, 2012a, 2012b, 2012c; Vereecken et al., 2016). Hence, a need exists for upscaling schemes that enable one to convert point scale data to much larger extents.

Coarse scale characteristics of the soil hydraulic parameters are governed predominantly by soil texture and structure (especially at the field scale), and topography (especially at watershed scales and beyond) (Jana, 2010). Topography plays a key role in soil classification. Several studies have shown that topography-based scaling algorithms are able to capture much of the variations in soil hydraulic parameters required to generate equivalent flows and soil moisture states in a coarsened domain (Wilson et al., 2004; Jana and Mohanty, 2012a, 2012b).

Practical methods for estimating soil moisture continuously over time and relatively large spatial areas likely involve a combination of remote sensing and modeling (Entekhabi et al., 1999; Vereecken et al., 2014). Recent studies have demonstrated that profile soil moisture could be estimated well by assimilation of remotely sensed surface soil moisture data into a hydrological model (Das et al., 2008a; Ines and Mohanty, 2008a, 2009; Montzka et al., 2011; Han et al., 2013, 2014; De Lannoy and Reichle, 2016; Vereecken et al., 2016). Despite the important role of surface and subsurface soil moisture in hydrological and meteorological predictions, detailed spatial and temporal modeling of profile soil moisture at the large scale is often still lacking.

During the past few decades, visible, near-infrared and shortwave infrared (Vis-NIR-SWIR) reflectance spectroscopy has been shown to be an effective alternative to conventional in-situ or laboratory methods for providing rapid, noninvasive and cost-effective estimates of a wide range of soil properties. Many studies have shown the capability of laboratory scale Vis-NIR-SWIR (400-2500 nm) spectrometry to accurately estimate basic soil properties such as the soil particle size distribution, organic carbon content, water content, and clay mineralogy (Gomez et al., 2008; Lopez et al., 2013; Minasny et al., 2008, among many others). These properties are at the same time key input parameters for many pedotransfer functions (PTFs) for estimating the unsaturated soil hydraulic properties (Vereecken et al., 2010). Despite extensive literature on predictions of basic soil properties from Vis-NIR-SWIR data, more research is needed to more directly and reliably estimate the soil hydraulic properties. A few studies recently analyzed the potential of soil spectral information in the Vis-NIR-SWIR region to estimate soil hydraulic properties using point (Janik et al., 2007; Minasny et al., 2008; Lagacherie et al., 2008; Babaeian et al., 2015b) and parametric (Santra et al., 2009; Babaeian et al., 2015b) transfer functions. These studies provided soil hydraulic parameters at point scale. While some scale mismatch between mostly point measurements of the soil hydraulic parameters and hydrological models appears to be unavoidable, a better understanding of the required upscaling process is very much needed.
While the advantages of PTFs have been demonstrated for quantifying soil hydraulic properties (e.g., Vereecken et al., 1989; Schaap et al., 2001; Homaee and Farrokhian Firouzi, 2008; Ghorbani Dashtaki et al., 2010; Khodaverdiloo et al., 2011), they are rarely implemented in hydrologic models where a broad definition and application of soil types still dominate simulations of soil moisture. Parametric PTFs provide soil hydraulic parameters that could be used directly in hydrological models. Guber et al. (2009) compared a number of published PTFs and the HYDRUS-1D model (Šimůnek et al., 2005) to simulate water flow in a soil profile.

The spectral behavior of a soil is a dynamic soil property that can undergo rapid changes because of changes in soil composition due to, for example, agricultural activities, soil erosion and biological processes. Using spectral data as PTF input provides an effective way of including the temporal processes in hydrological models. Babaeian et al. (2015a, $2015 b)$ recently derived and validated the accuracy of spectrotransfer functions (STFs) and spectral pedotransfer functions (SPTFs) to predict the unsaturated soil hydraulic properties. STFs relate the hydraulic properties directly with spectral reflectance parameters, while SPTFs use additional basic soil data such as the particle size distribution and bulk density.

In this paper we present a study to test the effectiveness and robustness of coarse-scale derived parametric PTFs, STFs, and SPTFs by studying surface, near-surface and subsurface soil water dynamics in a semiarid region, the Zanjanrood River sub-watershed (ZRS), in northwestern Iran. The accuracy of simulated surface soil water states is tested against estimates from microwave satellite imagery. Our primary objective was to assess coarse scale values of the van Genuchten-Mualem soil hydraulic parameters (van Genuchten, 1980) to simulate surface, near-surface and subsurface soil water dynamics at the $1 \mathrm{~km} \times 1 \mathrm{~km}$ domain/pixel size, while incorporating the influence of the local topography into the aggregation algorithm. Reference soil water states for comparison were obtained from the advanced synthetic aperture radar (ASAR) through the IEM algorithm developed by Rahman et al. (2008). Our findings will help to assess the value of air- and space-borne hyperspectral data for studying the spatio-temporal dynamics of profile soil water contents.

\section{Materials and methods}

\subsection{Study area}

The Zanjanrood River sub-watershed (ZRS), located in the northwestern part of Iran, was selected as the test area for our study. The ZRS area of approximately $250 \mathrm{~km}^{2}$ was chosen for its variety in terrain and land use characteristics, soil type and soil distribution patterns (Fig. 1). The topography consists of level to slightly undulating slopes varying approximately from 0 to $4 \%$, with elevations ranging from approximately 1380 to $2160 \mathrm{~m}$ above mean sea level. The climate is semi-arid, with an average annual precipitation of $320 \mathrm{~mm}$. The maximum $\left(43^{\circ} \mathrm{C}\right)$ and minimum $\left(-30^{\circ} \mathrm{C}\right)$ yearly temperatures occur in $\mathrm{Au}-$ gust and January, respectively, while the average yearly temperature is about $11^{\circ} \mathrm{C}$. Soil texture varies from clay to sandy loam, with the majority of soils classified as clay loam and loam. Rain-fed agriculture with a land cover of wheat (75\%) and poor rangeland (25\%) dominate landuse in the area. Using Arc GIS FishNet tool (ESRI), the entire ZRS was divided into a grid of $1 \mathrm{~km} \times 1 \mathrm{~km}$ pixels to match the ASAR (global mode) pixels. We selected 20 pixels across the study area for analysis so that they represent different locations, soil types, topographies and land uses (see Fig. 1). A summary of various geophysical attributes of the selected pixels are given in Table 1.

\subsection{Numerical simulations}

The HYDRUS-1D software package was used to simulate vertical water flow in the soil domains (Šimůnek et al., 2005). HYDRUS-1D 


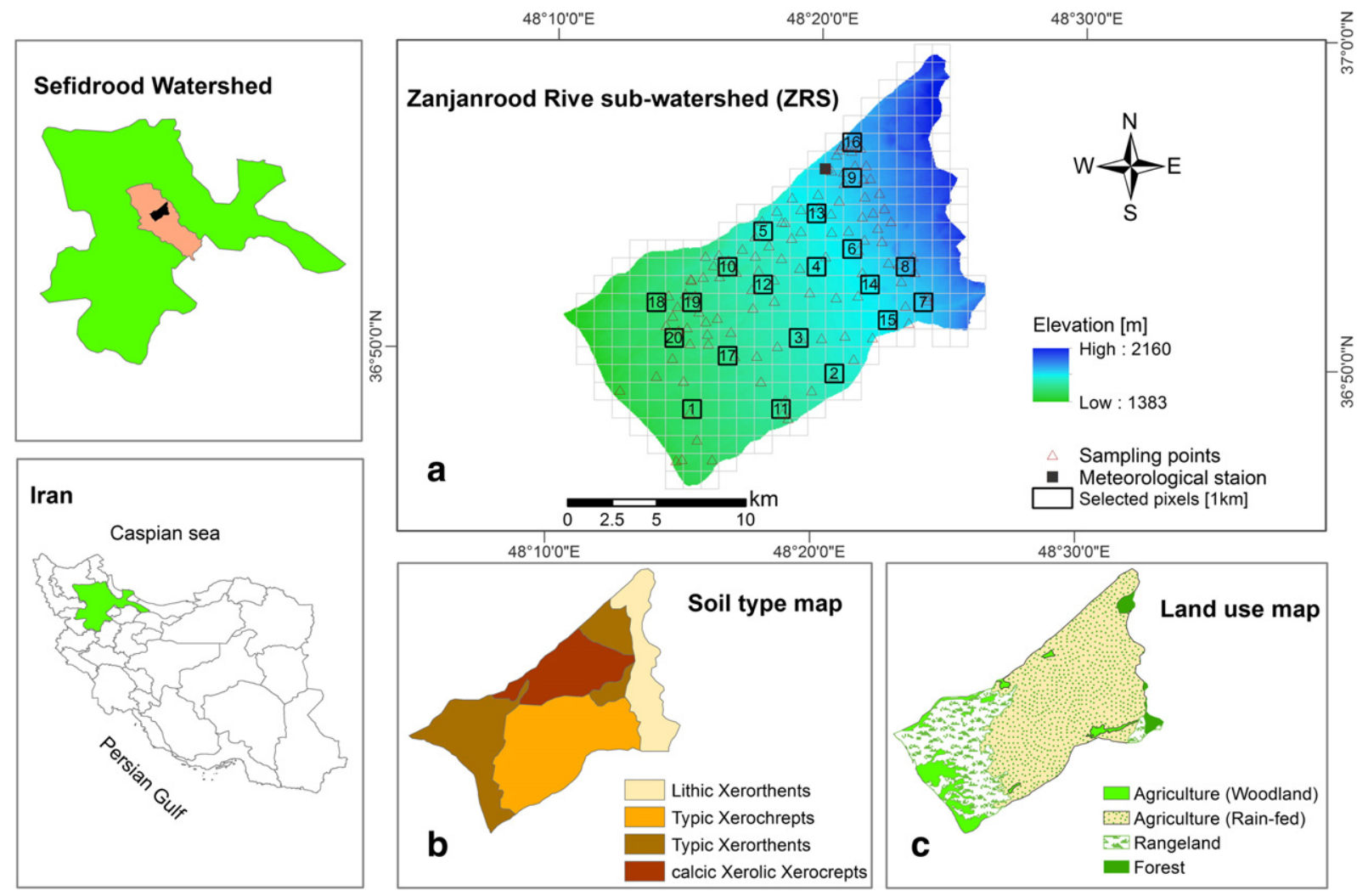

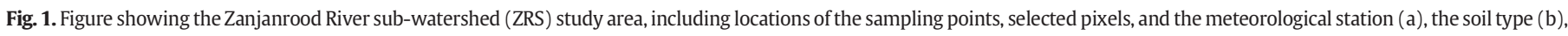
and land-use (c) maps.

uses the Richard's equation to simulate unsaturated flow, while incorporating a general sink term to account for root water uptake as follows:

$\frac{\partial \theta(h)}{\partial t}=\frac{\partial}{\partial z}\left[K(h) \frac{\partial h}{\partial z}-K(h)\right]-S$

where $\theta$ is the soil water content $\left[\mathrm{cm}^{3} \mathrm{~cm}^{-3}\right], h$ is the soil water pressure head $[\mathrm{cm}], z$ is soil depth $[\mathrm{cm}], t$ is time [d], $K$ is the hydraulic conductivity $\left[\mathrm{cm} \mathrm{d}^{-1}\right]$, and $S$ is the sink term $\left[\mathrm{d}^{-1}\right]$ (i.e., root water uptake).
For the soil hydraulic properties $(\theta(h)$ and $K(h))$ in Eq. (1), we used the original van Genuchten-Mualem (VGM) expressions as derived by van Genuchten (1980):

$K(h)=K_{s} \sqrt{S_{e}}\left[1-\left(1-S_{e}^{1 / m}\right)^{m}\right]^{2}$

Table 1

Land-use, average elevation, average slope, and soil texture classes of the selected ZRS pixels.

\begin{tabular}{|c|c|c|c|c|}
\hline & Dominant land-use & Average elevation (m) & Average slope (\%) & Dominant soil type \\
\hline Pixel 1 & Rangeland & 1529 & 1.81 & Clay loam \\
\hline Pixel 2 & Agriculture & 1682 & 1.94 & Clay loam \\
\hline Pixel 3 & Agriculture & 1671 & 1.85 & Clay loam \\
\hline Pixel 4 & Agriculture & 1719 & 2.28 & Clay loam \\
\hline Pixel 5 & Agriculture & 1691 & 1.95 & Clay loam \\
\hline Pixel 6 & Agriculture & 1779 & 3.04 & Clay loam \\
\hline Pixel 7 & Agriculture & 1826 & 3.56 & Clay loam \\
\hline Pixel 8 & Agriculture & 1846 & 4.16 & Clay loam \\
\hline Pixel 9 & Agriculture & 1832 & 3.40 & Clay loam \\
\hline Pixel 10 & Rangeland & 1577 & 2.13 & Loam \\
\hline Pixel 11 & Agriculture & 1612 & 1.93 & Loam \\
\hline Pixel 12 & Agriculture & 1660 & 1.75 & Loam \\
\hline Pixel 13 & Agriculture & 1752 & 2.50 & Loam \\
\hline Pixel 14 & Agriculture & 1770 & 2.70 & Loam \\
\hline Pixel 15 & Agriculture & 1771 & 2.30 & Loam \\
\hline Pixel 16 & Agriculture & 1859 & 3.15 & Loam \\
\hline Pixel 17 & Rangeland & 1589 & 2.30 & Sandy loam \\
\hline Pixel 18 & Rangeland & 1536 & 2.18 & Sandy loam \\
\hline Pixel 19 & Rangeland & 1632 & 2.38 & Sandy loam \\
\hline Pixel 20 & Rangeland & 1540 & 1.92 & Sandy clay loam \\
\hline
\end{tabular}

Spring wheat is the dominant agriculture in the region 

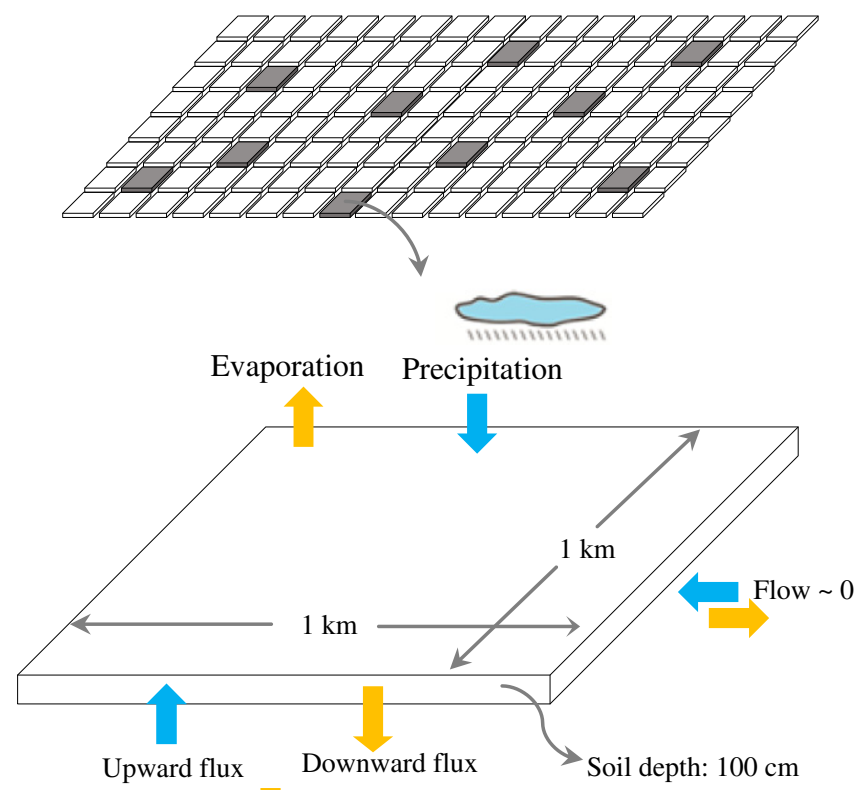

Free drainage

Fig. 2. A pixel-scale non-interacting and homogeneous soil profile used for the numerical experiment across the study area.

where $\theta_{r}$ and $\theta_{s}$ are the residual and saturated water contents, respectively $\left[\mathrm{cm}^{3} \mathrm{~cm}^{-3}\right], \alpha$ is an empirical shape parameter approximately equivalent to the inverse of the air entry value $\left[\mathrm{cm}^{-1}\right], n$ is a pore size distribution parameter [], and $m=1-1 / n$.

The numerical simulations were performed for all the 20 selected pixels of 100-cm deep soil profiles, where each pixel assumed to be representative of each $1 \mathrm{~km}^{2}$ pixel. We did not employ numerical simulations for the rest of the study area, because these 20 pixels were selected based on different locations, soil types, topographies and land uses and thus can be considered as an indicator of the whole study area. We used a non-interacting and homogeneous soil column approach (Vereecken et al., 2007) in which the soil hydraulic properties did not vary with depth (Fig. 2). The choice of uniform soils with depth is justified by the fact that the horizontal extent of the study domain (comprised of $1 \mathrm{~km} \times 1 \mathrm{~km}$ pixels) was much greater than the vertical profile (with $100-\mathrm{cm}$ depth). We hence assumed that the effects of changes in the soil properties versus depth due to layering close to the soil surface are relatively minor in the overall aggregation scheme.

The $100-\mathrm{cm}$ deep soil profiles were discretized into 200 non-equidistant finite elements having a size of $0.5 \mathrm{~mm}$ at the soil surface and a size of $35 \mathrm{~mm}$ at the lower boundary (Scharnagl et al., 2011). Atmospheric time-dependent boundary conditions and a free drainage condition $(\partial h / \partial z=0)$ were imposed at the upper and lower boundaries of the soil profiles. As initial condition we assumed a linearly decreasing water content from $0.4 \mathrm{~cm}^{3} \mathrm{~cm}^{-3}$ at the soil surface to $0.2 \mathrm{~cm}^{3} \mathrm{~cm}^{-3}$ at the bottom of the profile (Montzka et al., 2011). A 30-day spin-up time period was used to allow the assumed initial soil water distribution in each of the 20 pixels to align with the local weather conditions. After employing the aggregation scheme and providing coarse scale soil hydraulic parameters, each pixel area was considered flat from a run-off/ run-on perspective, thus assuming that water flow only occurred in the vertical direction.

Aggregated effective VGM parameters (see Section 2.3) were assigned to each selected coarse pixel. Wheat crops, being the dominant vegetation cover in the study area, are commonly planted in the end of March (DOY-90). Hence, we neglected transpiration and root water uptake processes due to sparsely vegetation cover, and only considered evaporation. The Penman-Monteith approach, as implemented in HYDRUS-1D, was used to estimate potential soil evaporation rates based on atmospheric forcing data from the meteorological station in the region (Šimůnek et al., 2008). We simulated a period of 100-days, starting on January 1,2012, with a temporal resolution of one day in the precipitation/potential evaporation data. Fig. 3 demonstrates the reference potential evapotranspiration (ET) and precipitation patterns during the study period.

\subsection{Aggregation algorithm}

The power average operator (PAO), a topography-based aggregation algorithm as described by Yager (2001), was used in this study to coarsen the measured and retrieved VGM soil hydraulic parameters. The PAO approach combines two aggregation methods, a mode-like method and
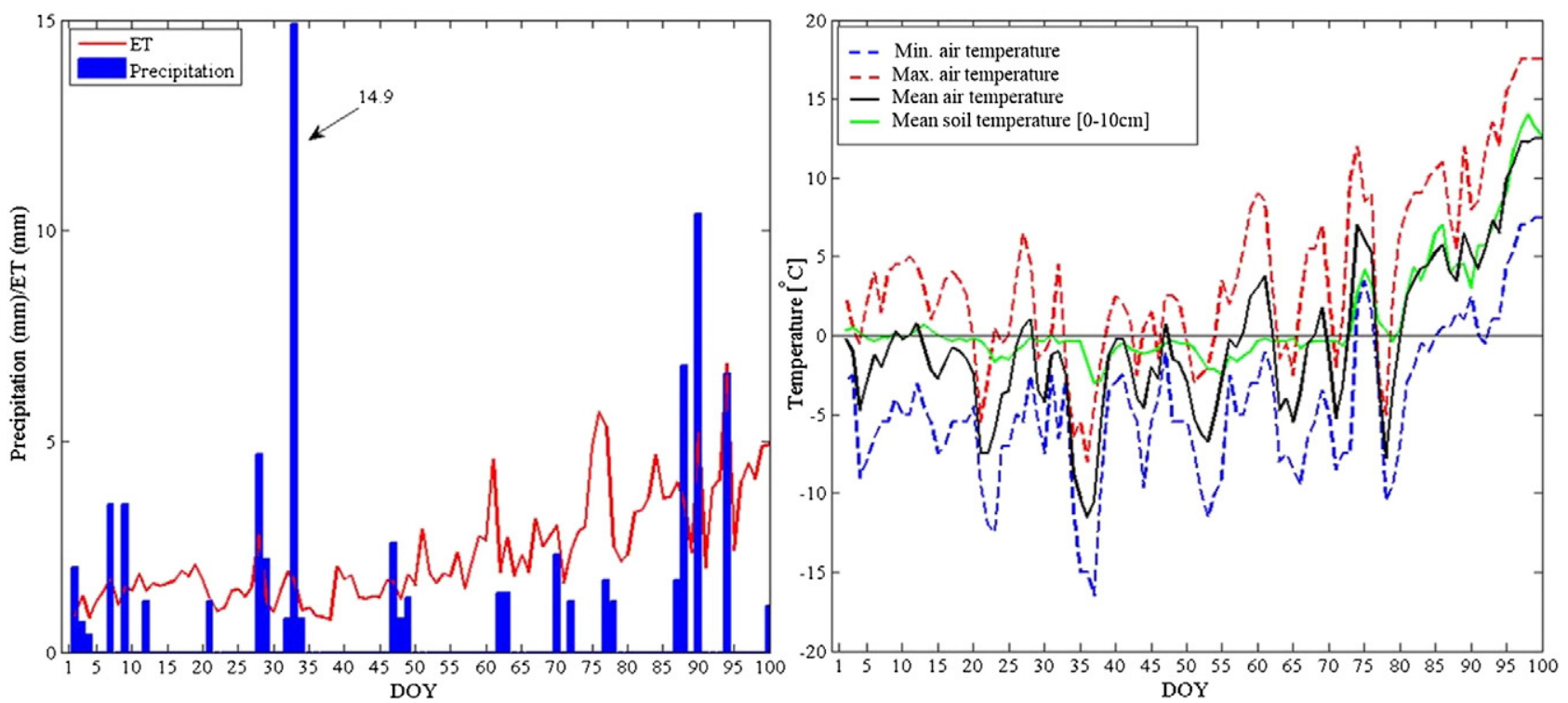

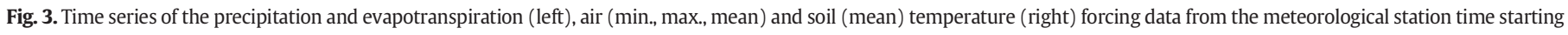
January 2012 
a mean type aggregation, to provide a very useful tool for coarse scale soil hydraulic parameters. In the mode-like method, the emphasis is on finding the most probable value of a parameter from a given set, while in mean-type aggregation the aim is to find the mean value of the given set. The PAO is defined as:

$P^{*}\left(p_{1}, p_{2}, \ldots, p_{n}\right)=\frac{\sum_{i=1}^{n}\left[1+T\left(p_{i}\right)\right] p_{i}}{\sum_{i=1}^{n}\left[1+T\left(p_{i}\right)\right]}$

in which

$$
T\left(p_{i}\right)=\sum_{\substack{i=1 \\ j \neq i}}^{n} \operatorname{Sup}\left(p_{i}, p_{j}\right)
$$

where $P^{*}$ is the power average of parameter values $p_{1}, p_{2}, \ldots, p_{n}, \operatorname{Sup}\left(p_{i}\right.$, $\left.p_{j}\right)$ is the support of $p_{i}$ from $p_{j}$ in which $\operatorname{Sup}\left(p_{i}, p_{j}\right) \in[0.1]$. A general form of the support equation is

$\operatorname{Sup}\left(p_{i}, p_{j}\right)=e^{-\eta\left(p_{i}-p_{j}\right)^{2}}$

where

$\eta=\left(\frac{z_{j_{\max }}-z_{j_{\min }}}{z_{i}-z_{j}}\right)^{2} \frac{\sqrt{\left(x_{i}-x_{j}\right)^{2}+\left(y_{i}-y_{j}\right)^{2}+\left(z_{i}-z_{j}\right)^{2}}}{S}$

where $\eta$ is the scale factor $(\eta \geq 0)), x, y$ and $z$ are the Cartesian coordinates of the point, and $S$ is the scale (resolution) to which the hydraulic parameters are being aggregated (i.e., $1 \mathrm{~km}$ ). In nature scale factor can be affected by many factors such as variation in atmospheric parameters, vegetation cover, soil type, distance between observations and topography. Here we constrained the other factors and considered $\eta$ as a function of difference in topography (elevation) and distance between sampling points.

A more detailed description of the PAO is provided by Jana and Mohanty (2012a, 2012b). The PAO was used separately for providing coarse scale VGM hydraulic parameters $\left(\mathrm{p}_{\mathrm{i}}\right)$ so that aggregated values (estimated/measured parameters) were obtained using the difference in distance (horizontal and vertical) between the sampling points and their values. The elevation data were used to determine vertical distance between the sample points.

\subsection{Radar model and soil water content retrieval}

The Integral Equation Model (IEM) is a widely used analytical and physically based radar backscatter model developed for bare soils (Zribi and Dechambre, 2002; Rahman et al., 2008). In general, IEM quantifies the backscattering coefficient as a function of soil water content and surface roughness, which are unknown, and the radar configuration:

$\sigma^{\circ}=f\left(h_{R M S}, L_{c}, \theta\right)$

where $\sigma$ is the backscattering coefficient [decibel, dB], $h_{R M S}$ is the root mean squared height variation of the surface at the centimeter scale [cm], $L_{c}$ is the correlation length of the height variation, and $\theta$ is the soil water content as before.

Zribi and Dechambre (2002) indicated that differences in the backscatter coefficient, $\Delta \sigma^{\circ}$, generated with the IEM model using two different incidence angles while keeping all other parameters constant, is proportional to the surface roughness only. They also found that $\Delta \sigma^{\circ}$ is proportional to the ratio of $h_{R M S}$ and $L_{C}$ :

$h_{R M S}^{2} / L_{c}=g\left(\Delta \sigma^{\circ}\right)$

Using the backscatter coefficient obtained for dry surface conditions $\left(\sigma_{d r y}^{\circ}\right)$, it is possible to derive both $h_{R M S}$ and $L_{C}$ as follows:

$\sigma_{\text {dry }}^{\circ}=h\left(h_{R M S}, L_{c}\right)$

Using Eqs. (9) and (10), and substituting terms, it is possible to solve for the two roughness parameters, $h_{R M S}$ and $L_{c}$, to obtain

$L_{c}=\omega\left(\Delta \sigma^{\circ}, \sigma_{d r y}^{\circ}\right)$

$h_{R M S}=\phi\left(\Delta \sigma^{\circ}, \sigma_{d r y}^{\circ}\right)$

The resulting roughness parameters are used to parameterize the IEM model and to retrieve the soil water content. The values of the roughness parameters can be then substituted in Eq. (9):

$\sigma_{\text {moist }}^{\circ}=\lambda\left(\Delta \sigma^{\circ}, \sigma_{d r y}^{\circ}, \theta\right)$

which can be inverted to obtain the soil water content:

$\theta=\lambda^{-1}\left(\Delta \sigma^{\circ}, \sigma_{d r y}^{\circ}, \sigma_{\text {moist }}^{\circ}\right)$

We used the method developed by Rahman et al. (2008) to provide estimates of roughness parameters $\left(h_{R M S}, L_{c}\right)$ from multi-angle radar images at two incidence angles from two dry images in August and September 2011. Dry backscatter coefficient $\left(\sigma_{\text {dry }}^{\circ}\right)$ was also obtained from ASAR images in this two dates. We used Next ESA SAR Toolbox (NEST) software (https://earth.esa.int/web/nest) for computing backscatter coefficients.

\subsection{Data collection and analysis}

Basic soil attributes (i.e., clay content, silt content, sand content, bulk density, organic carbon content and geometric mean of the soil particle diameter) and VGM hydraulic parameters (i.e., $\theta_{r}, \theta_{s}, \alpha, n$ and $K_{s}$ ) of the ZRS study area were obtained for 174 soil samples (point scale with average distance about $1.5 \mathrm{~km}$ ) collected from the study area using a combination of relatively standard field soil sampling procedures and laboratory measurements (Dane and Topp, 2002). The saturated hydraulic conductivity was measured using constant- and falling-head methods in the laboratory. Gravimetric water contents were measured at nine matric potentials (i.e., $0,-5,-10,-330,-1000,-3000$, $-5000,-10,000$, and $-15,000 \mathrm{~cm}$ ) of the water retention curve using sand-box apparatus and pressure plate extractor methods in the laboratory (Vereecken et al., 2010). Using nonlinear least-squares optimization, the retention models were fitted to the measured soil-water content values to obtain the hydraulic parameters (see also Babaeian et al., 2015a, 2015b for more details). These laboratory-based hydraulic parameters were considered as observed VGM parameters.

Using these basic soil properties and laboratory-measured spectral reflectance data in the visible, near-infrared and shortwave-infrared region (350-2500 nm), three different types of parametric transfer functions were developed to provide estimated sets of hydraulic parameters. The transfer functions included spectral transfer functions (STFs), pedotransfer function (PTFs) and spectral pedotransfer functions (SPTFs). A detailed description of how the soil spectral data were processed and used to derive the transfer functions is given by Babaeian et al. (2015b).

The PAO aggregation scheme was subsequently used to aggregate $i$ ) estimated VGM parameters from the transfer functions, and ii) observed 
VGM parameters from the laboratory so that they could be used to simulate soil water dynamics at the pixel scale $(1 \mathrm{~km} \times 1 \mathrm{~km})$. The soil profile for this purpose was divided into three layers: 0 to 5,5 to 10 , and 10 to $30 \mathrm{~cm}$. The three parameters $\alpha, n$ and $\theta_{s}$ in Eq. [2] and the one additional parameter $K_{s}$ in Eq. [3], were estimated for each layer using the derived parametric STFs, PTFs and SPTFs proposed by Babaeian et al. (2015b). Briefly, the parametric STFs, PTFs and SPTFs are simple linear regression equations which use spectral data, basic soil properties and spectral based basic soil predictions, respectively, as their inputs to estimate VGM parameters. In-situ soil water content data $(n=15)$ of the bare profiles were collected using time domain reflectometry (TDR) method (Topp et al., 1980) at five different times and at two depths ( $z$ $-0-10 \mathrm{~cm}, \mathrm{z}-30 \mathrm{~cm}$ ) along transects within one field site (with area $\sim 1 \mathrm{~km}^{2}$ ) close to the meteorological station (Fig. 1). Elevation data were provided at a $30 \mathrm{~m}$ resolution. Meteorological data (e.g., daily precipitation, maximum and minimum temperature, relative humidity, wind speed and solar radiation) were obtained from a meteorological station located north of the study area (Fig. 1) for the months of January through March 2012. Time series of daily average precipitation and evapotranspiration are shown in Fig. 3. As can be seen, relatively wet and dry periods alternated during the study period.

Using ENVISAT/ASAR active microwave data (C-band, Global Mode with a resolution of $1 \mathrm{~km} \times 1 \mathrm{~km}$, ascending pass) and the inversion algorithm of IEM, surface soil water contents were retrieved for 13 days of the year 2012. The sensor measured the total soil backscatter at pixels of $1 \mathrm{~km} \times 1 \mathrm{~km}$, as stated earlier, which were then used to provide soil water estimates. Surface roughness values needed for the IEM model were derived from a set of two ASAR images at dry soil conditions, covering the study area at different view angles (Verhoest et al., 2008). In order to validate the estimates, we used measured surface soil water contents at the field scale. ASAR-based surface soil water contents within the study area, valid for the top centimeter of the soil (Mohanty et al., 2013; Adams et al., 2013), were considered as a basis to evaluate simulated surface soil water contents obtained with HYDRUS-1D. We used the mean error (ME), the root mean squared error (RMSE) and Pearson's correlation coefficient $(r)$ of the simulated and measured
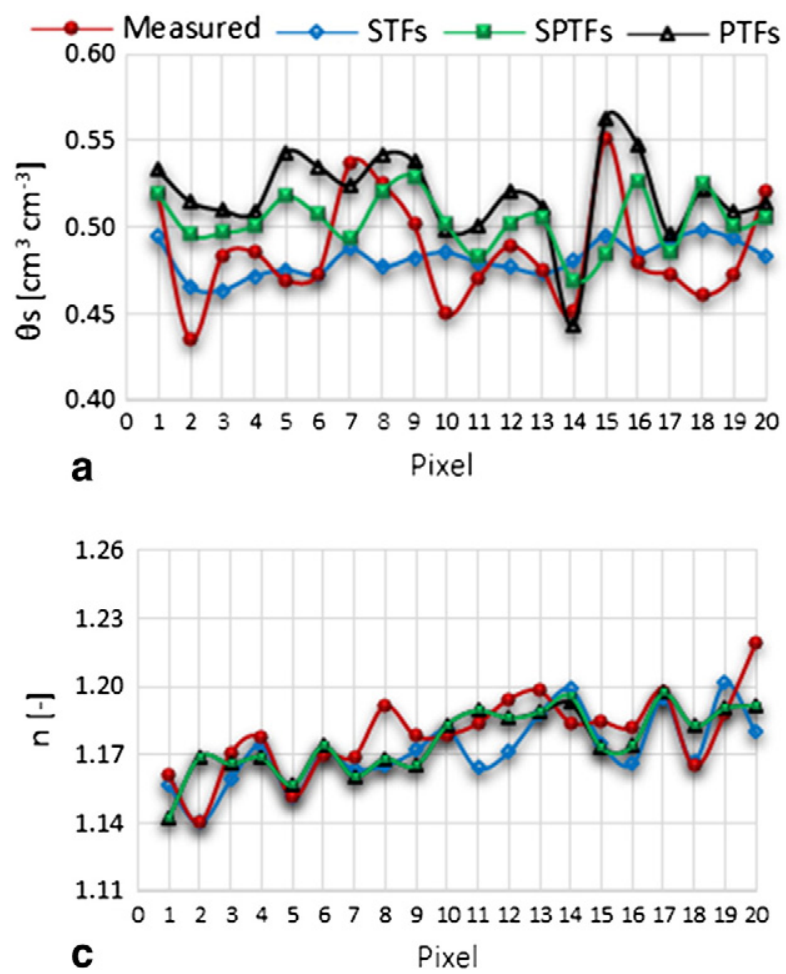

values to evaluate the accuracy of our numerical experiments and the performance of the coarse scale transfer functions (Zarei et al., 2010):

$M E=\frac{1}{N} \sum_{i=1}^{N}\left(S_{i}-M_{i}\right)$

$R M S E=\sqrt{\frac{1}{N} \sum_{i=1}^{N}\left(S_{i}-M_{i}\right)^{2}}$

$r=\frac{\sum_{i=1}^{N}\left(S_{i}-\bar{S}\right)\left(M_{i}-\bar{M}\right)}{\sqrt{\sum_{i=1}^{N}\left(S_{i}-\bar{S}\right)^{2} \sum_{i=1}^{N}\left(M_{i}-\bar{M}\right)^{2}}}$

where $S_{i}$ and $M_{i}$ denote the $i$ th simulated (estimated) and measured values, $\bar{S}$ and $\bar{M}$ are means of simulations (estimations) and measured values respectively, $N$ is the number of data pairs consisting of $S_{i}$ and $M_{i}$. Also, we added the $p$ value ( 1 and $5 \%$ ) of the correlations.

\section{Results and discussion}

3.1. Accuracy of coarse scale transfer functions for the VGM hydraulic parameters

In this section we show the performance of the PAO scheme in terms of coarse scale soil hydraulic parameters and providing effective values of the VGM parameters. Fig. 4 shows a comparison between observed and estimated VGM hydraulic parameters that were aggregated using the PAO scaling scheme from the fine scale to the $1 \mathrm{~km}^{2}$ coarse resolution for the 20 selected pixels ( $1 \mathrm{~km} \times 1 \mathrm{~km}$ ) within the study area. As can be seen, the coarse scale estimates for each parameter are slightly different from the coarse scale observations. Relatively large differences were observed for the saturated water content, $\theta_{s}$ (Fig. 4a). The coarse scale transfer functions (estimated VGM parameters) showed a similar and very close trend with the observed values of $\alpha, n$ and $\ln K s$ across
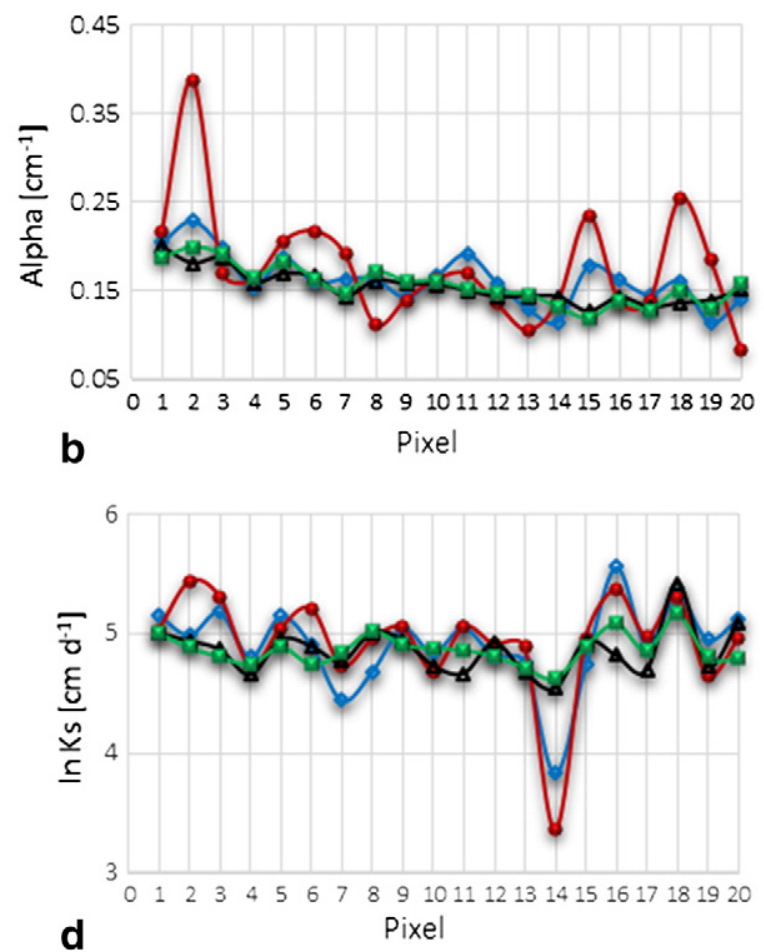

Fig. 4. Aggregated values of the estimated and observed VGM hydraulic parameters for 20 pixels across the ZRS. 
Table 2

Comparison between coarse-scale estimated and observed VGM hydraulic parameters across all selected pixels of the ZRS.

\begin{tabular}{|c|c|c|c|c|c|c|c|c|}
\hline \multirow[t]{2}{*}{ Coarse scale } & \multicolumn{2}{|c|}{$\theta s\left[\mathrm{~cm}^{3} \mathrm{~cm}^{-3}\right]$} & \multicolumn{2}{|c|}{$\alpha\left[\mathrm{cm}^{-1}\right]$} & \multicolumn{2}{|l|}{$n[-]$} & \multicolumn{2}{|c|}{$\ln K s\left[\mathrm{~cm} \cdot \mathrm{d}^{-1}\right]$} \\
\hline & $r$ & RMSE & $r$ & RMSE & $r$ & RMSE & $r$ & RMSE \\
\hline STFs & 0.321 & 0.0294 & $0.648^{b}$ & 0.0545 & $0.703^{b}$ & 0.0148 & $0.863^{b}$ & 0.2471 \\
\hline PTFs & $0.554^{\mathrm{b}}$ & 0.0427 & 0.309 & 0.0676 & $0.655^{\mathrm{b}}$ & 0.0137 & $0.555^{\mathrm{a}}$ & 0.3678 \\
\hline SPTFs & 0.123 & 0.0374 & 0.366 & 0.0656 & $0.659^{\mathrm{b}}$ & 0.0139 & $0.681^{\mathrm{b}}$ & 0.3774 \\
\hline
\end{tabular}

$\mathrm{r}$ and RMSERMSE are correlation coefficient and root mean squared error, respectively. Superscripts 'a' and 'b' represent significance at the 0.05 and 0.01 levels, respectively.

all pixels (Figs $4 \mathrm{~b}, \mathrm{~d}$ ). The coarse scale transfer functions overestimated $\theta_{s}$ for most of the pixels, with the largest value being for the PTFs ( $\mathrm{ME}=$ $0.034)$ and the smallest one for the STFs $(\mathrm{ME}=0.005)$. The coarse scale transfer functions slightly underestimated $\alpha, n$ and $\ln K s$ of most pixels, with $\ln \left(K_{s}\right)$ having the largest ME values $(-0.066,-0.064$ and -0.013 for the PTFs, SPTFs and STFs, respectively), and $n$ having smallest ME values (ME $=-0.007,-0.003$ and -0.003 for the STFs, PTFs and SPTFs, respectively).

Table 2 provides a comparison between VGM parameters from the coarse scale transfer functions and those obtained from coarsening the observed values, in terms of Pearson's correlation coefficient ( $r$ ) and RMSE information for providing effective VGM parameters. As indicated, coarse scale STFs performed the best for parameters $\alpha$ ( $r=0.648$, $p<0.01$, and RMSE $=0.0545), n(r=0.703, p<0.01$, and RMSE $=$ $0.0148)$ and $\ln K s(r=0.863, \mathrm{p}<0.01$, and RMSE $=0.2471)$, followed by the coarse scale SPTFs. By comparison, the $r$ values for $\theta_{s}$ were quite low $(r<0.55)$. The coarse scale PTFs performed best for $\theta_{s}$, having $r$ and RMSE values equal to $0.554(\mathrm{p}<0.01)$ and 0.0427 , respectively. Overall, the strong and significant correlations between the coarsescale estimated and observed VGM parameters are indications that the PAO scheme used to aggregate the fine scale soil hydraulic parameters is providing an appropriate set of VGM hydraulic parameters at the coarse scale.

\subsection{Coarse scale transfer functions and soil water dynamics}

The temporal dynamics of soil water contents of the selected pixels at three soil depths as simulated using the three sets of coarse scale transfer functions are shown in Figs. 5, 6 and 7, along with the observed values (using measured VGM parameters) and ASAR estimates. The three curves in each plot represent daily model outputs of the water content using the coarse scale led transfer functions. Two additional curves show the fine- and coarse-scale daily outputs when observed VGM parameters were used in the forward run. Ground-truth measurements of soil water and ASAR estimates are marked by symbols. As expected, the surface soil $(z-0-1 \mathrm{~cm})$ exhibited more variations in the soil water contents (range between 0.10 and $0.45 \mathrm{~cm}^{3} \mathrm{~cm}^{-3}$ ) than the other two depths where the variations are gradually weakened (Figs. 6 and 7).

Results indicate that at the beginning of the simulated period, due to several precipitation events, the surface layer nearly reached saturation. Soil water contents reflected rapid infiltration of water during precipitation events at DOY 29, 34, 90 and 94 due to dry soil condition. During the strongest precipitation events (i.e., DOY 34, 91 and 95), the upper and lower soil layers reached saturation, which persisted for several days. At the mid of the simulation period (DOY between 50 and 90), the soil surface dried out rapidly within a few days, with water contents reaching a constant value of about $0.15 \mathrm{~cm}^{3} \mathrm{~cm}^{-3}$. This was due in part to used residual water content $\left(\theta_{r}=0.05\right)$, initial/boundary conditions, and less precipitation, while evaporation rates continued from the surface soil. The evapotranspiration (ET) values (see Fig. 3) are larger than precipitation values between DOY 50 and 88 . So this could result in non-response to the precipitation events during this period.

According to the meteorological station data, on several days, however, the mean air and soil temperatures went down to below $0{ }^{\circ} \mathrm{C}$ (see Fig. 3). It should be noted that these values were obtained from one meteorological station located in the northwest of the study area and elevation about $1800 \mathrm{~m}$. This was consistent with the presence of a snow cover and a frozen surface soil as observed in the meteorological station site. Infiltration and water flow is essentially non-existent in a frozen soil.

The results of Figs. 5, 6 and 7 also show that the transfer functionbased soil water signatures closely followed each other as well as the observed (fine and coarse scale) signatures for most pixels. A comparison of the various curves gives additional information about the role of precipitation as a key factor controlling surface soil water status. For example, the coarse scale transfer functions produced very similar time series that were shifted in various degrees with respect to each other. The scatter in the simulated water contents was found to be substantial at the deeper layers, particularly during dry period (Figs. 6 and 7). Notice further that simulations obtained with the coarse-scale transfer

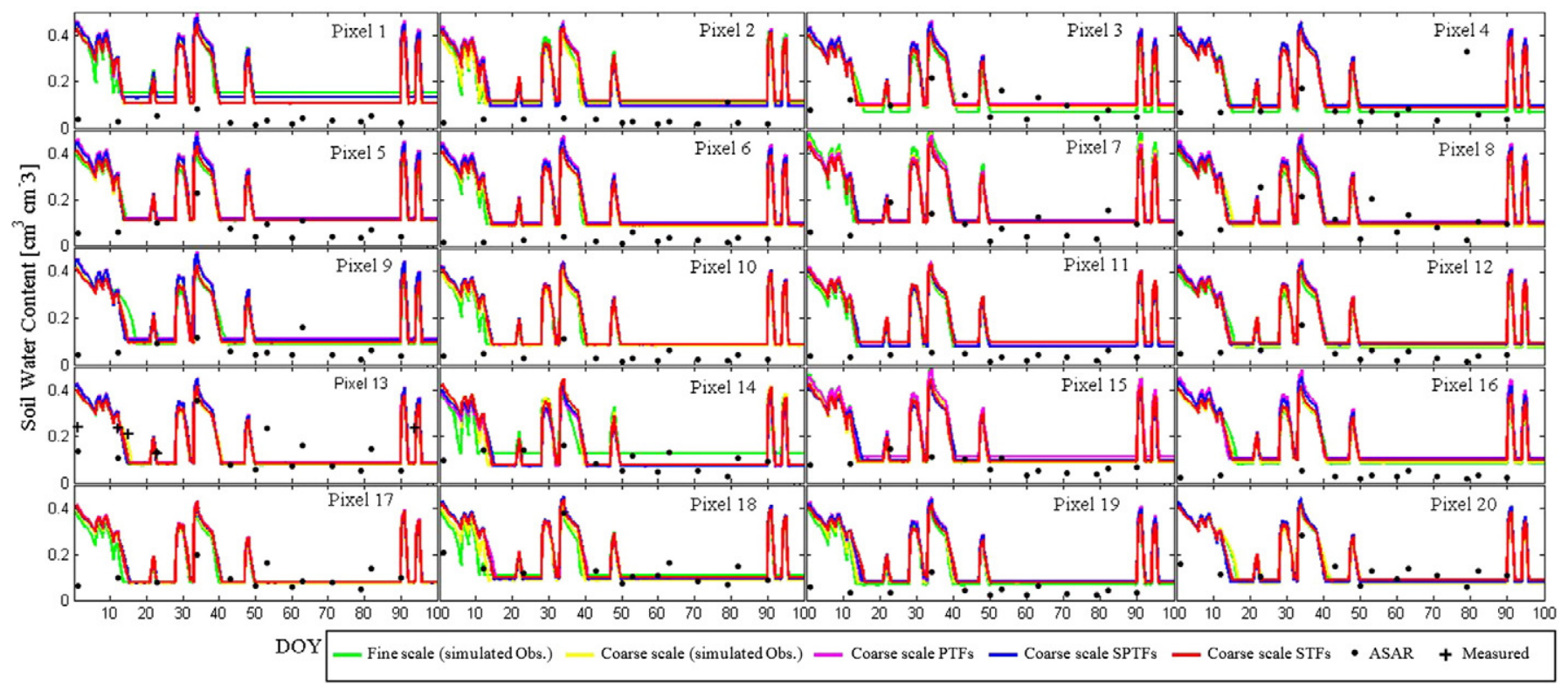

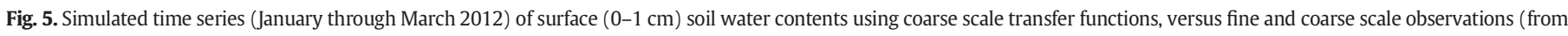
observed VGM parameters) and ASAR-based estimates for 20 pixels of the ZRS study site. Ground-truth (measured) values are shown for pixel 13. 


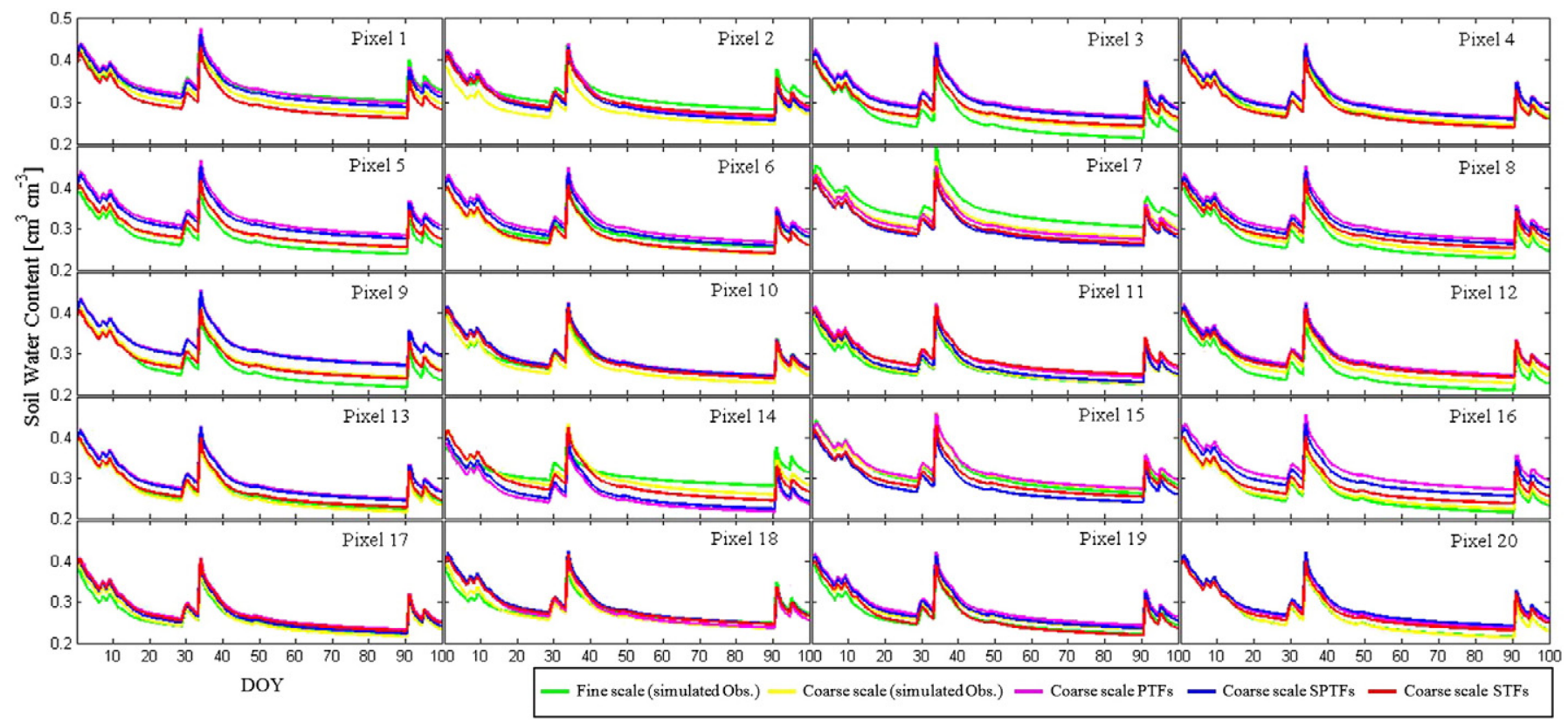

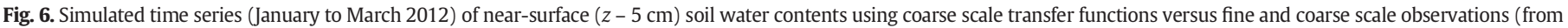
observed VGM parameters) for 20 pixels of the ZRS study site.

functions continuously over-predicted soil water contents of the near$(z-5 \mathrm{~cm})$ and subsurface $(z-30 \mathrm{~cm})$ layers. The coarse scale PTFs and SPTFs also tended to over-predict the water contents of most pixels.

Fig. 8 shows ME and the RMSE values between the average daily soil water contents for the selected pixels at three soil depths as obtained using the coarse-scale observed VGM parameters and those calculated using three different sets of coarse scale transfer functions in the HYDRUS-1D simulations. As can be seen, for most of the pixels at three soil depths, the coarse scale STFs performed the best with mean RMSE and ME values of 0.012 and $0.004 \mathrm{~cm}^{3} \mathrm{~cm}^{-3}$, respectively, followed by the coarse scale SPTFs (mean RMSE and ME equal to 0.019 and $0.010 \mathrm{~cm}^{3} \mathrm{~cm}^{-3}$, respectively) and the PTFs (mean RMSE and ME equal to 0.021 and $0.015 \mathrm{~cm}^{3} \mathrm{~cm}^{-3}$, respectively). While the simulated water contents were overestimated in many pixels, in general they were reasonable accurate. This signifies that the simulated soil water contents were relatively close to the reference values. Results suggest the feasibility of using spectral data to estimate VGM parameters and predict the soil water dynamic at the larger scale.

\subsection{Comparison of simulated soil water contents with ASAR estimates}

Fig. 5 illustrates average daily soil water contents of the surface soil $(z-0-1 \mathrm{~cm})$ as simulated using the coarse-scale observed VGM parameters and those obtained with the coarse scale transfer functions, along with the ASAR-based estimates for the selected pixels. As can be seen, the estimated (ASAR) and simulated soil water trends show a good match with the precipitation pattern (see Figs. 3 and 5).

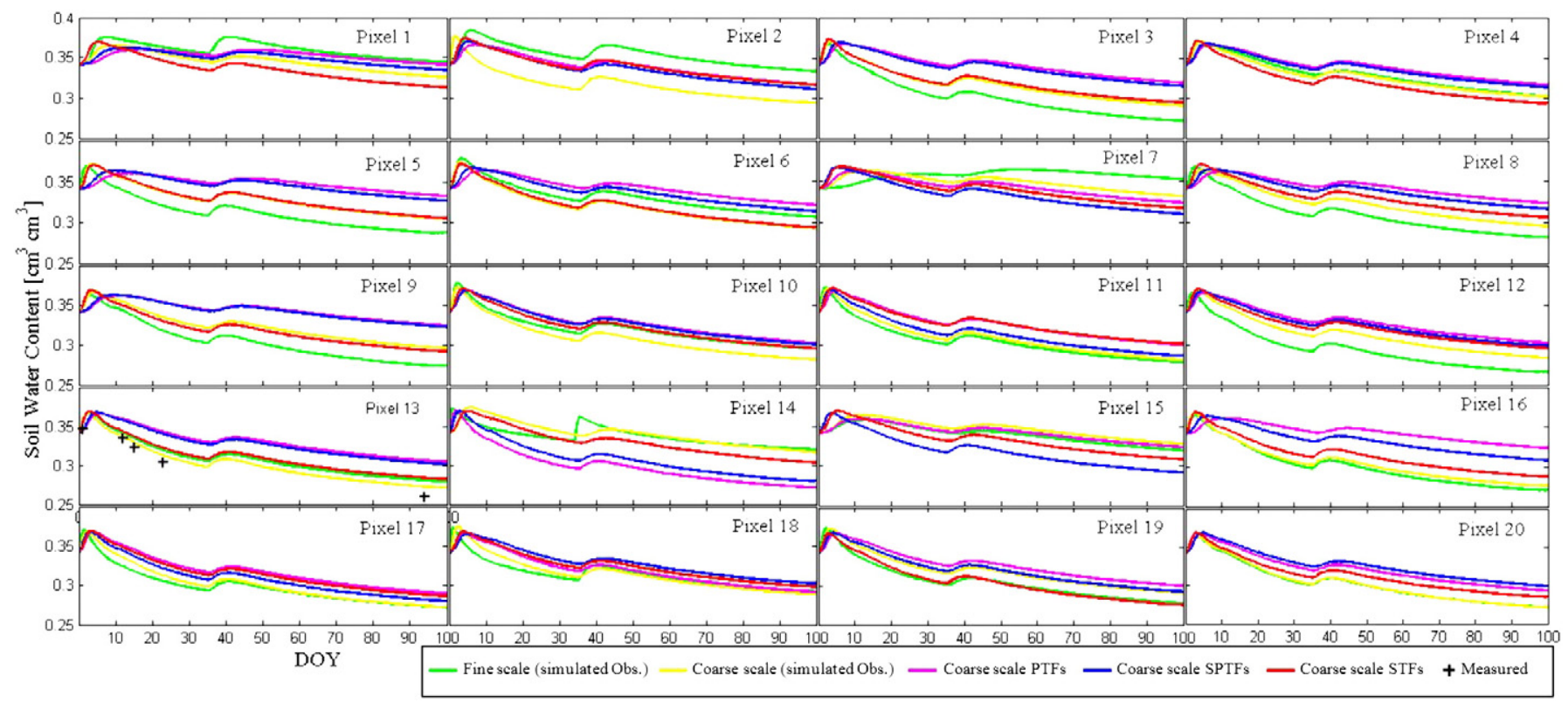

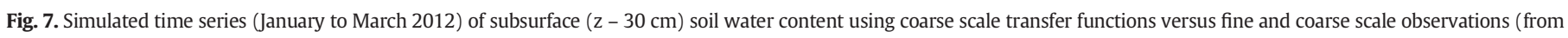
observed VGM parameters) for 20 pixels of the ZRS study site. Ground-truth (measured) values are shown for pixel 13. 


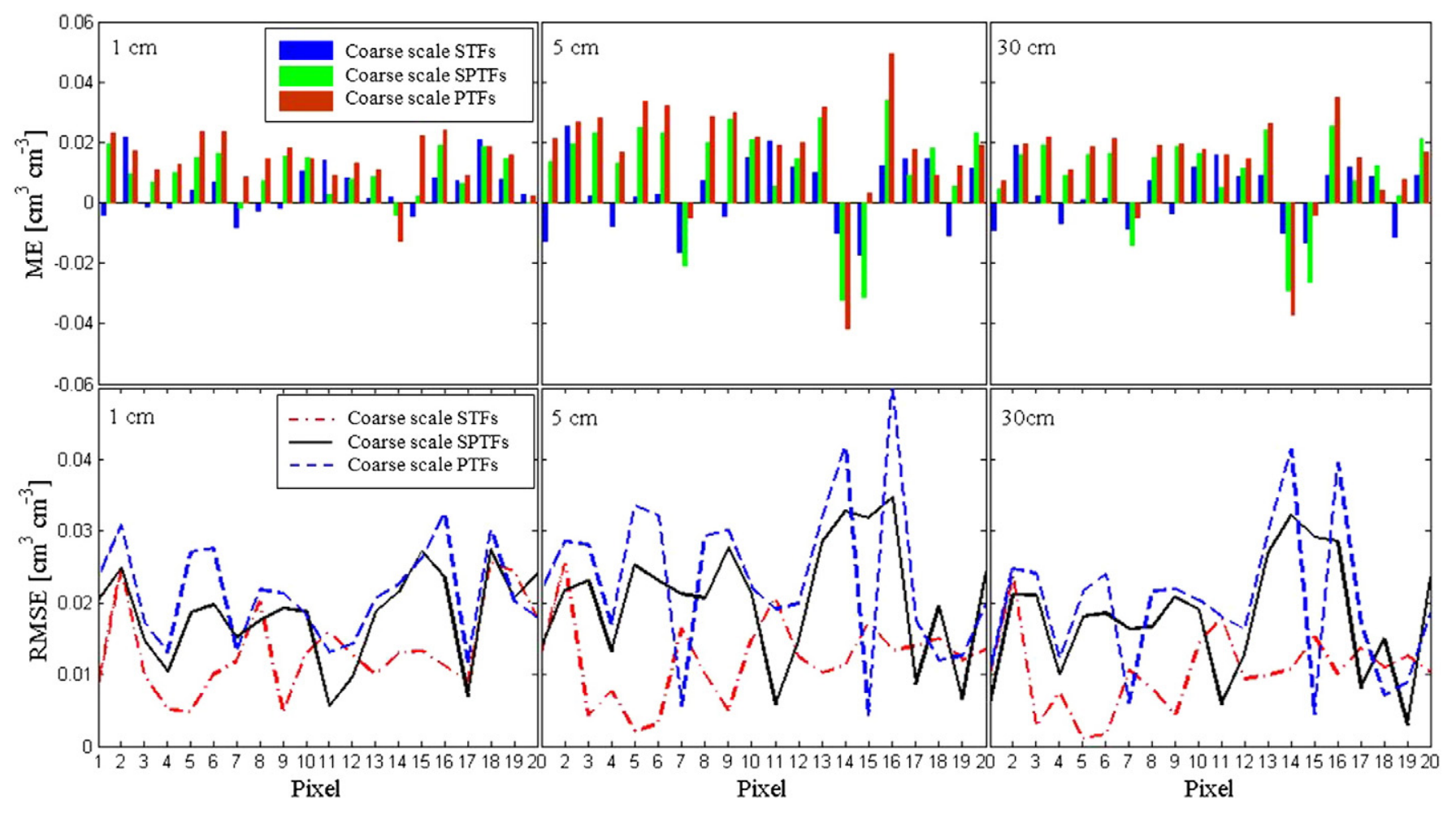

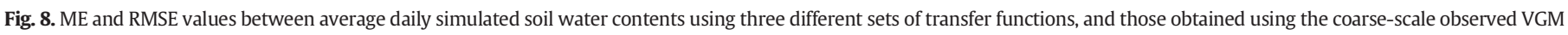
parameters for each pixel at three soil depths.

We found that the lowest simulated soil water contents were about $0.10 \mathrm{~cm}^{3} \mathrm{~cm}^{-3}$, while the ASAR-based estimates were less than the simulated values $\left(<0.10 \mathrm{~cm}^{3} \mathrm{~cm}^{-3}\right)$ (Fig. 5). This indicates that the ASAR data were more sensitive during relatively dry conditions. Except for a few cases, the ASAR estimates produced lower water contents for about half of the selected pixels (i.e., pixels 1, 2, 6, 9, $10,11,12,1516$ and 19) during the study period. This may point out that the probability of underestimation is about $50 \%$. However, more investigations are needed to improve our estimations. This difference in water contents may be attributed to soil roughness () and soil freezing (Jagdhuber et al., 2014). They pointed out that as soon as the soil temperatures fall below $0{ }^{\circ} \mathrm{C}$, a distinct drop occurs in the dielectric constant for all soil types. This then keeps the dielectric level close to the lower physical limit for all freezing states (Jagdhuber et al., 2014). In such case, the soil medium will show dielectric properties of a dry soil.

Part of the differences may be due also to some differences in the effective sensing depths of the ASAR sensor and TDR probes (Wang et al., 2011). The surface layer of a soil is commonly drier than the subsurface layers, particularly in arid and semi-arid regions (Wang et al., 2011). ASAR signals (C-band, $5.33 \mathrm{GHz}$ ) essentially perceive the dielectric properties of the surface soil layer (at about $1 \mathrm{~cm}$ or less). For the TDR-based ground-truth measurements we used for the validation, the detected water content is the integral value of the entire sampled layer $(0-10 \mathrm{~cm})$ in the measured soil volume. This could partly explain the underestimation of the water content, as suggested also in the literature. However, this does not explain all of the underestimated soil water measurements. Another source of errors may be related to assumptions about the roughness estimation. In our study the surface roughness was considered to be temporally stable, with the roughness parameterizations assuming dielectric properties for dry soil conditions, while soil management practices (e.g., agricultural land preparation, soil erosion) may change the surface roughness between relatively dry and wet periods. Soil roughness can also change due to change in soil water conditions.
Correlations of the average daily water contents simulated with the coarse scale transfer functions with those from the ASAR-based estimates are given in Table 3. The data show that the average simulated surface water contents from the coarse scale transfer functions generated good correlations with ASAR estimates for all pixels across wet, intermediate and dry days, with the r-values being between 0.10 and 0.84 . Significant correlations were found for pixels 1, 4, 5, 10, 12, 13, 18, 19, 20 , which showed $r$ values between 0.62 and 0.84 . This may illustrate that the probability of $50 \%$ for correlation/uncorrelation within these pixels. However, no significant differences in correlations were observed between simulated water contents from the coarse scale transfer functions (Table 3).

\subsection{Comparison of average simulated soil water contents and ground-truth measurements}

For each coarse scale transfer function, we analyzed the r, ME and RMSE of simulated water contents for the surface $(z-0-1 \mathrm{~cm})$ and subsurface $(z-30 \mathrm{~cm})$ soil layers for which ground-truth measurements (defined as measured) and ASAR estimates were available. Results are shown in Table 4. While the previous section provided insight into the performance of the PAO scheme with respect to providing effective VGM hydraulic parameters, the ultimate test of the practical applicability of the scheme is how well the simulated soil water states match the measurements. Accordingly, we compared the coarse-scale simulated water contents to the average of the values $(n=15)$ from one experimental field site, which arithmetically were resampled to the $1 \mathrm{~km}$ scale, as well as the remotely sensed ASAR soil water estimates. Our approach could be validated only for one pixel (pixel 13) because of a lack of sufficient in-situ measurements. Still, this provides a base of judging the performance and robustness of the coarse scale transfer functions and the hydrologic simulation model.

Table 4 shows that for surface layer the correlations were relatively good ( $r$ values between 0.499 and 0.581 ), but that the biases (errors) between the simulated and the ground-truth measurements were 
Table 3

Correlation coefficient $(r)$ between simulated soil water content from coarse scale transfer functions and ASAR-based estimates ( $\mathrm{z}-0$ - $1 \mathrm{~cm}$ ) for the selected pixels at ZRS.

\begin{tabular}{|c|c|c|c|c|}
\hline & Coarse scale STFs & Coarse scale SPTFs & Coarse scale PTFs & Coarse scale measurements \\
\hline Pixel 1 & $0.62^{\ddagger}$ & $0.63^{\ddagger}$ & $0.65^{\ddagger}$ & $0.62^{\ddagger}$ \\
\hline Pixel 2 & 0.10 & 0.10 & 0.10 & 0.10 \\
\hline Pixel 3 & 0.51 & 0.51 & 0.51 & 0.50 \\
\hline Pixel 4 & $0.62^{\ddagger}$ & $0.62 \ddagger$ & $0.63 \ddagger$ & $0.62^{*}$ \\
\hline Pixel 5 & $0.73^{\S}$ & $0.75^{\S}$ & $0.75^{\S}$ & $0.73^{\S}$ \\
\hline Pixel 6 & 0.09 & 0.10 & 0.10 & 0.10 \\
\hline Pixel 7 & 0.36 & 0.35 & 0.36 & 0.37 \\
\hline Pixel 8 & 0.28 & 0.26 & 0.26 & 0.24 \\
\hline Pixel 9 & 0.31 & 0.33 & 0.33 & 0.32 \\
\hline Pixel 10 & $0.82^{\S}$ & $0.82^{\S}$ & $0.82^{\S}$ & $0.82^{\S}$ \\
\hline Pixel 11 & 0.24 & 0.24 & 0.24 & 0.24 \\
\hline Pixel 12 & $0.82^{\S}$ & $0.82^{\S}$ & $0.81^{\S}$ & $0.80^{\S}$ \\
\hline Pixel 13 & $0.72^{\S}$ & $0.73^{\S}$ & $0.73^{\S}$ & $0.71^{\S}$ \\
\hline Pixel 14 & 0.57 & 0.57 & 0.57 & 0.56 \\
\hline Pixel 15 & 0.33 & 0.32 & 0.32 & 0.32 \\
\hline Pixel 16 & 0.56 & 0.56 & 0.57 & 0.56 \\
\hline Pixel 17 & 0.49 & 0.49 & 0.49 & 0.49 \\
\hline Pixel 18 & $0.84^{\S}$ & $0.84^{\S}$ & $0.83^{\S}$ & $0.87^{\S}$ \\
\hline Pixel 19 & $0.72^{\S}$ & $0.73^{\S}$ & $0.73^{\S}$ & $0.75^{\S}$ \\
\hline Pixel 20 & $0.73^{\S}$ & $0.75^{\S}$ & $0.74^{\S}$ & $0.71^{\S}$ \\
\hline
\end{tabular}

Superscripts $\ddagger$ and $\S$ represent $\mathrm{p}<0.05$ and $\mathrm{p}<0.01$ respectively.

considerable (RMSE values between 0.107 and $0.138 \mathrm{~cm}^{3} \mathrm{~cm}^{-3}$ and ME values between 0.004 and $-0.015 \mathrm{~cm}^{3} \mathrm{~cm}^{-3}$ ). For the subsurface layer, however, the transfer functions were found to perform much better than for the surface layer. At the fine scale and in the subsurface layer, the simulated water contents matched the in-situ measurements very well $\left(r=0.999, \mathrm{ME}=0.016\right.$ and RMSE $\left.=0.015 \mathrm{~cm}^{3} \mathrm{~cm}^{-3}\right)$. At the pixel scale, the simulated soil water dynamics also closely matched the in-situ measurements. The best results were obtained with the coarse-scale observed hydraulic parameters $(r=0.995, \mathrm{ME}=0.010$, RMSE $=0.009 \mathrm{~cm}^{3} \mathrm{~cm}^{-3}$ ) and the estimated hydraulic parameters from the STFs $\left(r=0.998, \mathrm{ME}=0.018\right.$, RMSE $\left.=0.018 \mathrm{~cm}^{3} \mathrm{~cm}^{-3}\right)$, followed by the SPTFs $\left(r=0.896, \mathrm{ME}=0.033\right.$, RMSE $=0.034 \mathrm{~cm}^{3}$ $\left.\mathrm{cm}^{-3}\right)$ and PTFs $\left(r=0.871, \mathrm{ME}=0.035\right.$, RMSE $\left.=0.036 \mathrm{~cm}^{3} \mathrm{~cm}^{-3}\right)$, with the SPTFs and PTF performing very similarly. These field validation results support the robustness of the coarse scale spectral transfer functions as shown earlier also in Section 3.2.

\section{Summary and conclusions}

In this paper we presented results of the newly developed diffuse spectral reflectance-based transfer functions of Babaeian et al. (2015a, 2015b), and used a topography-based aggregation scheme

Table 4

Summary of performance of the coarse scale transfer functions in simulating surface $(z-0-1 \mathrm{~cm})$ and subsurface $(z-30 \mathrm{~cm})$ soil water contents for the pixel 13 of the ZRS study site.

\begin{tabular}{llll}
\hline & \multicolumn{2}{l}{ Simulated versus Measured } & \\
\cline { 2 - 4 } & $\mathrm{r}$ & $\mathrm{ME}$ & RMSE \\
\hline $\mathrm{z}-0-1 \mathrm{~cm}$ & & & \\
Fine scale (Obs.) & 0.537 & 0.027 & 0.132 \\
Coarse scale (Obs.) & 0.581 & 0.004 & 0.107 \\
Coarse scale PTFs & 0.532 & -0.010 & 0.140 \\
Coarse scale SPTFs & 0.499 & -0.010 & 0.138 \\
Coarse scale STFs & 0.578 & -0.015 & 0.123 \\
$\mathrm{z}-$ - 30 cm & & & \\
Fine scale (Obs.) & $0.999^{* *}$ & 0.016 & 0.015 \\
Coarse scale (Obs.) & $0.995^{* *}$ & 0.010 & 0.009 \\
Coarse scale PTFs & 0.871 & 0.035 & 0.036 \\
Coarse scale SPTFs & $0.896^{*}$ & 0.033 & 0.034 \\
Coarse scale STFs & $0.998^{* *}$ & 0.018 & 0.018 \\
\hline * and ** represent $\mathrm{p}<0.05$ and $\mathrm{p}<0.01$, respectively. & &
\end{tabular}

(PAO) to assess coarse-scale transfer functions (i.e., STFs, SPTFs and PTFs). The ultimate objective was to predict surface and near-surface soil water dynamics at a semi-arid region, ZRS, in northwestern Iran. Using the PAO algorithm, which is based only on topographic attributes (elevation), we aggregated point-scale estimated and observed VGM hydraulic parameters to a coarse resolution (1 $\mathrm{km}^{2}$ pixel size). The equivalence of the coarse scale transfer functions was subsequently tested by simulating soil water dynamics for 20 pixels through the watershed. Simulated soil water contents of the surface and subsurface layers were compared across scale, and also with the ground-truth measurements as well as with those made using the ASAR spaceborne radar sensor in combination with the IEM model.

We found significant correlations between aggregated values of the estimated and observed VGM hydraulic parameters for the selected pixels of the ZRS site. The coarse scale STFs performed the best for parameters $\alpha, n$ and $\ln K s$, followed by the coarse scale SPTFs. The coarse scale PTFs performed best for $\theta_{s,}$. The coarse scale STFs performed best in simulating surface and near-surface soil water dynamics in terms of RMSE and ME values, followed by the coarse scale SPTFs and PTFs, which produced very similar results. While the simulated water contents were slightly overestimated in many pixels, in general they produced reasonable accurate values. Average simulated water contents of the surface layer showed significant correlations with the ASAR estimates for most pixels, particularly during wet periods. The simulated soil water dynamics matched the ground-truth measurements well, especially in the root zone layer.

Overall, the PAO scheme used to aggregate the fine-scale soil hydraulic parameters provided a useful set of VGM hydraulic parameters for the coarse scale. Our findings point out the feasibility of using spectral data to estimate VGM hydraulic parameters and, ultimately, to provide predictions in time and space of prevailing soil water contents. Future work could be designed to implement and test this approach at the larger scale using air-borne and space-borne hyperspectral (e.g., EnMAP, Hyperion) and multi-spectral (e.g., Landsat-8, Sentinel-2) remote sensors. This study was conducted during the winter time, where soil water measurements through the experimental field were only available for a short period corresponding to this season. Since ASAR data is recorded in C-band, they significantly are affected by dense vegetation cover of agricultural lands in summer. Thus this could provide uncertain estimates of soil water during the summer time. 


\section{References}

Adams, J.R., Berg, A.A., McNairn, H., 2013. Field level soil moisture variability at 6-and 3$\mathrm{cm}$ sampling depths: implications for microwave sensor validation. Vadose Zone J. 12 (3). http://dx.doi.org/10.2136/vzj2012.0070.

Babaeian, E., Homaee, M., Montzka, C., Vereecken, H., Norouzi, A.A., 2015a. Towards retrieving soil hydraulic properties by hyperspectral remote sensing. Vadose Zone J. http://dx.doi.org/10.2136/V14.07.0080.

Babaeian, E., Homaee, M., Vereecken, H., Montzka, C., Norouzi, A.A., van Genuchten, M.T. 2015b. A comparative study of multiple approaches for predicting the soil water retention curve: hyperspectral information versus basic soil properties. Soil Sci. Soc. Am. J. http://dx.doi.org/10.2136/sssaj2014.09.0355.

Baghdadi, N., Aubert, M., Zribi, M., 2012. Use of TerraSAR-X data to retrieve soil moisture over bare soil agricultural fields. IEEE Geosci. Remote Sens. Lett. 9 (3), 512-516. http://dx.doi.org/10.1109/LGRS.2011.2173155.

Dane, J.H., Topp, G.C., 2002. Methods of soil analysis. Part 4, Physical Methods: Soil Science Society of America Book Series. Soil Science Society of America, Madison, WI.

Das, N.N., Mohanty, B.P., Cosh, M.H., Jackson, T.J., 2008. Modeling and assimilation of root zone soil moisture using remote sensing observation in Walnut Gulch watershed during SMEX04. Remote Sens. Environ. 112, 415-429.

De Lannoy, G.J., Reichle, R.H., 2016. Global assimilation of multiangle and multipolarization SMOS brightness temperature observations into the GEOS-5 catchment land surface model for soil moisture estimation. J. Hydrometeorol. 17 (2), 669-691.

Dimitrov, M., Vanderborght, J., Kostov, K.G., Debecker, B., Schulze Lammers, P., Damerow, L., Vereecken, H., 2015. Soil hydraulic parameters of bare soil plots with different soil structure inversely derived from L-band brightness temperatures. Vadose Zone J. 14 (8).

Dimitrov, M., Vanderborght, J., Kostov, K.G., Jadoon, K.Z., Weihermüller, L., Jackson, T.J., Bindlish, R., Pachepsky, Y., Schwank, M., Vereecken, H., 2014. Soil hydraulic parameters and surface soil moisture of a tilled bare soil plot inversely derived from L-band brightness temperatures. Vadose Zone J. 13 (1).

Entekhabi, D., Asrar, G.R., Betts, A.K., Beven, K.J., Bras, R.L., Duffy, C.J., Dunne, T., Koster, R.D., Lettenmaier, D.P., McLaughlin, D.B., Shuttleworth, W.J., van Genuchten, M.T., Wei, M.-Y., Wood, E.F., 1999. An agenda for land surface hydrology research and a call for the second international hydrological decade. Bull. Am. Meteorol. Soc. 80 (10), 2043-2058.

Famiglietti, J.S., Rudnicki, J.W., Rodell, M., 1998. Variability in surface moisture content along a hillslope transect: Rattlesnake Hill, Texas. J. Hydrol. 210 (1-4), 259-281.

Ghorbani Dashtaki, S., Homaee, M., Khodaverdiloo, H., 2010. Derivation and validation of pedotransfer functions for estimating soil water retention curve using a variety of soil data. Soil Use Manag. 26, 68-74.

Gomez, C., Lagacherie, P., Coulouma, G., 2008. Continuum removal versus PLSR method for clay and calcium carbonate content estimation from laboratory and airborne hyperspectral measurements. Geoderma 148, 141-148.

Greifeneder, F., Notarnicola, C., Bertoldi, G., Niedrist, G., Wagner, W., 2016. From point to pixel scale: an upscaling approach for in situ soil moisture measurements. Vadose Zone J. 15 (6).

Guar, N., Mohanty, B.P., 2013. Evolution of physical controls for soil moisture in humid and subhumid watersheds. Water Resour. Res. 49, 1-15.

Guber, A.K., Pachepsky, Y., van Genuchten, M.T., Simunek, J., Jacques, D., Nemes, A. Nicholson, T.J., Cady, R.E., 2009. Multimodel simulation of water flow in a field soil using pedotransfer functions. Vadose Zone J. 8, 1-10.

Han, X., Franssen, H.J.H., Montzka, C., Vereecken, H., 2014. Soil moisture and soil properties estimation in the community land model with synthetic brightness temperature observations. Water Resour. Res. 50 (7), 6081-6105.

Han, X., Hendricks Franssen, H.J., Li, X., Zhang, Y., Montzka, C., Vereecken, H., 2013. Joint assimilation of surface temperature and L-band microwave brightness temperature in land data assimilation. Vadose Zone J. 12 (3).

Homaee, M., Farrokhian Firouzi, A., 2008. Deriving point and parametric pedotransfer functions of some gypsiferous soils. Aust. J. Soil Res. 46, 219-227. http://dx.doi.org/ 10.1071/SR07161.

Ines, A.V.M., Mohanty, B., 2008a. Near-surface soil moisture assimilation to quantify effective soil hydraulic properties using genetic algorithm: I. Conceptual modeling. Water Resour. Res. 44, W06422. http://dx.doi.org/10.1029/2007WR005990 (2008a).

Ines, A.V.M., Mohanty, B., 2009. Near-surface soil moisture assimilation for quantifying effective soil hydraulic properties using genetic algorithms: II. Using airborne remote sensing dyring SGP97 and SMEX02. Water Resour. Res. 45, W01408. http://dx.doi. org/10.1029/2008WR007022.

Jagdhuber, T., Hajnsek, I., Bronstert, A., Papathanassiou, K.P., 2013. Soil moisture estimation under low vegetation cover using a multi-angular polarimetric decomposition. IEEE Trans. Geosci. Remote Sens. 51 (4), 2201-2215.

Jagdhuber, T., Stockamp, J., Hajnsek, I., Ludwig, R., 2014. Identification of soil freezing and thawing states using SAR polarimetry at C-band. Remote Sens. 6, 2008-2023. http:// dx.doi.org/10.3390/rs6032008.

Jana, R.B., 2010. Scaling Characteristics of Soil Hydraulic Parameters at Varying Spatial Resolutions, PhD Dissertation. Dep. of Biol. and Agric. Eng., Texas A\&M Univ., College Station, Tex.

Jana, R.B., Mohanty, B., 2012a. On topographic controls of soil hydraulic parameter scaling at hillslope scales. Water Resour. Res. 48, W02518. http://dx.doi.org/10.1029/ 2011WR011204 (2012a).

Jana, R.B., Mohanty, B., 2012b. A topography-based scaling algorithm for hydraulic parameters at hillslope scales: field testing. Water Resour. Res. 48, W02519. http://dx.doi. org/10.1029/2011WR011205.
Jana, R.B., Mohanty, B., 2012c. A comparative study of multiple approaches to soil hydraulic parameter scaling applied at the hillslope scale. Water Resour. Res. 48, W02520. http://dx.doi.org/10.1029/2010WR010185.

Janik, L.J., Merry, R.H., Forrester, S.T., Lanyon, D.M., Rawson, A., 2007. Rapid prediction of soil water retention using mid infrared spectroscopy. Soil Sci. Soc. Am. J. 71, 507-514

Jonard, F., Weihermuller, L., Jadoon, K.Z., Schwank, M., Vereecken, H., Lambot, S., 2011 Mapping field-scale soil moisture with L-band radiometer and ground-penetrating radar over bare soil. IEEE Trans. Geosci. Remote Sens. 49 (8), 2863-2875 (2011).

Joshi, C., Mohanty, B., 2010. Physical controls of near-surface soil moisture across varying spatial scales in an agricultural landscape during SMEX02. Water Resour. Res. 46, W12503. http://dx.doi.org/10.1029/2010WR009152.

Kerr, H.Y., 2007. Soil moisture from space. Where are we? Hydrogeol. J. 15 (1), 117-120.

Khodaverdiloo, H., Homaee, M., van Genuchten, M.T., Ghorbani Dashtaki, S., 2011. Deriving and validating pedotransfer functions for some calcareous soils. J. Hydrol. 399, 93-99.

Kornelsen, K.C., Coulibaly, P., 2013. Advances in soil moisture retrieval from synthetic aperture radar and hydrological applications. J. Hydrol. 476, 460-489.

Kornelsen, K.C., Coulibaly, P., 2014. Root-zone soil moisture estimation using data-driven methods. Water Resour. Res. 50 (4), 2946-2962.

Koster, R.D., 20 Coauthors, 2004. Regions of strong coupling between soil moisture and precipitation. Science 305, 1138. http://dx.doi.org/10.1126/science.1100217.

Lagacherie, P., Baret, F., Feret, J.B., Madeira Netto, J., Robbez-Masson, J.M., 2008. Estimation of soil clay and calcium carbonate using laboratory, field, and airborne hyperspectral measurements. Remote Sens. Environ. 112 (3), 825-835.

Lopez, L.R., Behrens, T., Schmidt, K., Stevens, A., Alexandre, J., Dematte, M., Scholten, T., 2013. The spectrum-based learner: a new local approach for modeling soil vis-NIR spectra of complex datasets. Geoderma 195, 268-279.

Merlin, O., Walker, J.P., Chehbouni, A., Kerr, Y., 2008. Towards deterministic downscaling of SMOS soil moisture using MODIS derived soil evaporative efficiency. Remote Sens. Environ. 112 (10), 3935-3946.

Minasny, B., McBratney, A.B., Tranter, G., Murphy, B.W., 2008. Using soil knowledge for the evaluation of mid-infrared diffuse reflectance spectroscopy for predicting soil physical and mechanical properties. Eur. J. Soil Sci. 59, 960-997.

Mohanty, B.P., Cosh, M., Lakshmi, V., Montzka, C., 2013. Remote sensing for vadose zone hydrology-a synthesis from the vantage point. Vadose Zone J. 12 (3). http://dx.doi. org/10.2136/vzj2013.07.0128.

Montzka, C., Grant, J.P., Moradkhani, H., Hendricks-Franssen, H.J., Weihermuller, L., Drusch, M., Vereecken, H., 2013. Brightness temperature and soil moisture validation at different scales during the SMOS validation campaign in the Rur and Erft catchments, Germany. IEEE Trans. Geosci. Remote Sens. 51 (3), 1728-1743.

Montzka, C., Moradkhani, H., Weihermuller, L., Franssen, H.J.H., Canty, M., Vereecken, H. 2011. Hydraulic parameter estimation by remotely-sensed top soil moisture observations with the particle filter. J. Hydrol. 399, 410-421.

Pellenq, J., Kalma, J., Boulet, G., Saulnier, G.M., Wooldridge, S., Kerr, Y., Chehbouni, A., 2003. A disaggregation scheme for soil moisture based on topography and soil depth. J. Hydrol. 276 (1), 112-127.

Rahman, M.M., Moran, M.S., Thoma, D.P., Bryant, R., Collins, C.D., Jackson, T., Orr, B.J. Tischler, M., 2008. Mapping surface roughness and soil moisture using multi-angle radar imagery without ancillary data. Remote Sens. Environ. 112, 391-402.

Robinson, D.A., Abdu, H., Lebron, I., Jones, S.B., 2012. Imaging of hill-slope soil moisture wetting patterns in a semi-arid oak savanna catchment using timelapse electromagnetic induction. J. Hydrol. 416, 39-49.

Rosenbaum, U., Bogena, H.R., Herbst, M., Huisman, J.A., Peterson, T.J., Weuthen, A., Western, A.W., Vereecken, H., 2012. Seasonal and event dynamics of spatial soil moisture patterns at the small catchment scale. Water Resour. Res. 48 (W10544), 2012 http://dx.doi.org/10.1029/2011WR011518.

Santra, P., Sahoo, R.N., Das, B.S., Samal, R.N., Pattanaik, A.K., Gupta, V.K., 2009. Estimation of soil hydraulic properties using proximal spectral reflectance in visible, near-infrared, and shortwave-infrared (VIS-NIR-SWIR) region. Geoderma 152, 338-349.

Schaap, M.G., Leij, F.J., van Genuchten, M.T., 2001. ROSETTA: a computer program for estimating soil hydraulic parameters with hierarchical pedotransfer functions. J. Hydrol. 251, 163-176.

Scharnagl, B., Vrugt, J.A., Vereecken, H., Herbst, M., 2011. Inverse modelling of in situ soil water dynamics: investigating the effect of different prior distributions of the soil hydraulic parameters. Hydrol. Earth Syst. Sci. 15, 3043-3059. http://dx.doi.org/10.5194/ hess-15-3043-2011.

Schröter, I., Paasche, H., Dietrich, P., Wollschläger, U., 2015. Estimation of catchment-scale soil moisture patterns based on terrain data and sparse TDR measurements using a fuzzy C-means clustering approach. Vadose Zone J. 14 (11).

Šimůnek, J., van Genuchten, M.T., Šejna, M., 2005. The HYDRUS-1D software package for simulating the one-dimensional movement of water, heat, and multiple solutes in variably saturated media. Version 3.0, HYDRUS Software Series 1. Department of Environmental Sciences, University of California Riverside, Riverside, CA (270 p).

Šimůnek, J., van Genuchten, M.T., Šejna, M., 2008. Development and applications of the HYDRUS and STANMOD software packages and related codes. Vadose Zone J. 7, 587-600.

Topp, G.C., Davis, J.L., Annan, A.P., 1980. Electromagnetic determination of soil water content: measurements in coaxial transmission lines. Water Resour. Res. 16 (3), 574-582.

Ulaby, F.T., Dubois, P.C., van Zyl, J., 1996. Radar mapping of surface soil moisture. J. Hydrol. 184 (1-2), 57-84.

van Genuchten, M.T., 1980. A closed-form equation for predicting the hydraulic conductivity of unsaturated soils. Soil Sci. Soc. Am. J. 44, 892-898.

Vanderborght, J., Huisman, J.A., van der Kruk, J., Vereecken, H., 2013. Geophysical methods for field-scale imaging of root zone properties and processes. In: Anderson, S.H., 
Hopmans, J.W. (Eds.), Soil-Water-Root Processes: Advances in Tomography and Imaging. Soil Science Society of America, Madison, WI, pp. 247-281.

Vereecken, H., Huisman, J.A., Bogena, H., Vanderborght, J., Vrugt, J.A., Hopmans, J.W., 2008 On the value of soil moisture measurements in vadose zone hydrology: a review. Water Resour. Res. 44, W00D06. http://dx.doi.org/10.1029/2008WR006829 (2008).

Vereecken, H., Huisman, J.A., Pachepsky, Y., Montzka, C., van der Kruk, J., Bogena, H., Weihermuller, L., Herbst, M., Martinez, G., Vanderborght, J., 2014. On the spatio-temporal dynamics of soil moisture at the field scale. J. Hydrol. 516, 76-96.

Vereecken, H., Kasteel, R., Vanderborght, J., Harter, T., 2007. Upscaling hydraulic properties and soil water flow processes in heterogeneous soils: a review. Vadose Zone J. 6, 1-28. http://dx.doi.org/10.2136/vzj2006.0055.

Vereecken, H., Maes, J., Feyen, J., Darius, P., 1989. Estimating the soil moisture retention characteristic from texture, bulk density, and carbon content. Soil Sci. 148, 389-403.

Vereecken, H., Schnepf, A., Hopmans, J.W., Javaux, M., Or, D., Roose, T., Vanderborght, J. Young, M.H., Amelung, W., Aitkenhead, M., Allison, S.D., 2016. Modeling soil processes: review, key challenges, and new perspectives. Vadose Zone J. 15 (5).

Vereecken, H., Weynants, M., Javaux, M., Pachepsky, Y., Schaap, M.G., Genuchten, M.T. 2010. Using pedotransfer functions to estimate the van Genuchten-Mualem soil hydraulic properties: a review. Vadose Zone J. 9 (4), 795-820.

Verhoest, N.E., Lievens, H., Wagner, W., Álvarez-Mozos, J., Moran, M.S., Mattia, F., 2008. On the soil roughness parameterization problem in soil moisture retrieval of bare surfaces from synthetic aperture radar. Sensors 8 (7), 4213-4248.
Wang, S.G., Li, X., Han, X.J., Jin, R., 2011. Estimation of surface soil moisture and roughness from multi-angular ASAR imagery in the watershed allied telemetry experimental research (WATER). Hydrol. Earth Syst. Sci. 15, 1415-1426.

Weihermuller, L., Huisman, J.A., Lambot, S., Herbst, M., Vereecken, H., 2007. Mapping the spatial variation of soil water content at the field scale with different ground penetrating radar techniques. J. Hydrol. 340 (3-4), 205-216.

Wilson, D.J., Western, A.W., Grayson, R.B., 2004. Identifying and quantifying sources of variability in temporal and spatial soil moisture observations. Water Resour. Res. 40 (2), W02507. http://dx.doi.org/10.1029/2003 WR002306 (2004).

Yager, R.R., 2001. The power average operator. IEEE Trans. Syst. Man Cybern. Syst. Hum. 31 (6), 724-731.

Zarei, G., Homaee, M., Liaghat, A.M., Hoorfar, A.H., 2010. A model for soil surface evaporation based on Campbell's retention curve. J. Hydrol. 380, 356-361.

Zhu, J., Mohanty, B., 2002a. Spatial averaging of van Genuchten hydraulic parameters for steady state flow in heterogeneous soils. Vadose Zone J. 1 (2), 261-272.

Zhu, J., Mohanty, B., 2002b. Upscaling of hydraulic properties for steady state evaporation and infiltration. Water Resour. Res. 38, 1178. http://dx.doi.org/10.1029/2001 WR000704.

Zribi, M., Dechambre, M., 2002. A new empirical model to retrieve soil moisture and roughness from C-band radar data. Remote Sens. Environ. 84, 42-52. 